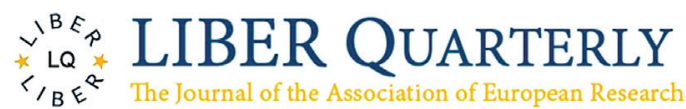

Vol. 30, (2020) 1-33 I e-ISSN: 2213-056X

\title{
The First Swedish Read \& Publish agreement: An Evaluation of the Springer Compact Pilot
}

\section{Lisa Olsson}

Stockholm University, Sweden

lisa.olsson@su.se, orcid.org/0000-0003-2289-4378

\section{Helena Francke}

Faculty of Librarianship, Information, Education and IT, University of Borås, Sweden

helena.francke@hb.se, orcid.org/0000-0001-5572-8566

\section{Camilla Hertil Lindelöw}

National Library of Sweden

Camilla.lindelow@kb.se, orcid.org/0000-0002-3331-0940

\section{Niklas Willén}

Uppsala University Library, Sweden

niklas.willen@ub.uu.se

\begin{abstract}
In this paper we summarise the lessons learned from the first Swedish Read \& Publish agreement: Springer Compact with Springer Nature (201607-01-2018-12-31). We set out to put the Swedish agreement in an international context and to examine the effects of the agreement regarding economy, publication outcome, administration and researchers' attitudes
\end{abstract}


and practices in Sweden. Publication data, economic data, as well as survey data from administrative staff and corresponding authors were collected and analysed. Based on the analyses, the advantages and disadvantages of Read \& Publish agreements are discussed. The advantages include increase in Open Access (OA) publishing, improved OA workflows and ease for researchers. The disadvantages include the risk of conserving the current system and its associated high costs.

Keywords: Springer compact; open access; evaluation; big deals; read \& publish

\section{Introduction}

The National Library of Sweden, through the Swedish library consortium, Bibsam, negotiates license agreements for electronic journals and databases on behalf of 85 Swedish universities, government agencies, and research institutes. One of the main goals of Bibsam today is to transform the publishing system with the goal of reaching 100 \% Open Access (OA) by 2020. Among others, LIBER (2017), Efficiency Standards for Article Charges (ESAC, 2018), Jisc (2018) and cOAlition S (2018) have provided valuable guidelines to support negotiations for such a transition.

In this paper, OA publishing is defined as research results that are disseminated online and freely available to everyone. Approximately $40 \%$ of Swedish research was published OA in 2017. Of these, just under $20 \%$ of the Swedish publications were published OA in their primary form in fully OA outlets and just over $10 \%$ were published OA in hybrid journals in 2017 (National Library of Sweden, 2019).

Active measures need to be taken to accelerate the OA publishing rate and to transform scholarly communication business models from subscriptionbased to pay-to-publish, to make the results of publicly funded research accessible to all. As a mean to reach this goal, Bibsam negotiated a Springer Compact pilot with Springer Nature ${ }^{1}$. In this paper, we report on findings from an evaluation of the agreement which was conducted on behalf of the Bibsam consortium steering group. The evaluation looked at the effects of the agreement regarding economy, publication outcome, administration and researchers' attitudes and practices in Sweden, and also did a comparison to Springer Compact agreements in other countries. 


\section{Publishers' Business Models and New Sources of Revenue}

The shift to OA has led to the development of new business models and new sources of income for the publishers. The total cost of scholarly publishing has increased, since the cost now includes not only subscription costs but also costs for (different sorts of) OA publishing. The cost components and the development of these business models are noted in the following.

\subsection{Article Processing Charges, Offsetting and Transformative Agreements}

We distinguish between three types of journals:

1. Subscription-based journals where OA publishing is not offered,

2. Hybrid journals where OA is offered if an Article Processing Charge (APC) is paid (in otherwise subscription-based journals),

3. Fully OA journals where all publications are OA (see Directory of Open Access Journals, DOAJ²).

There are two types of fully OA journals:

- Those where publishing is free of charge and funding is achieved through other means than charges for publishing. That is, $71 \%$ of the 11,001 journals in DOAJ (Morrison, 2018).

- Those which charge APCs.

Agreements intended to transform publishers' business models from subscription-based to OA have typically entailed an offset, a conditioned compensation of some sort (Science Europe, 2016). In the context of OA and academic publishing, it has meant that the funds that used to cover subscription costs are shifted to cover the costs of OA publishing (through APCs) in the journals, primarily hybrid journals, of a given publisher. There are different types of offsetting:

1. A pure Offset agreement means that an institution reduces its subscription costs with a publisher, based on the APCs the researchers from the institution paid for publishing OA during the previous year.

2. The second kind of offset model is the Read \& Publish. In these agreements, one publishing charge and one reading charge are paid. The 
reading charge is said to compensate for all articles still not $\mathrm{OA}$ in the journals. (Those who wish to emphasise that a larger charge funds publishing and a smaller charge funds reading will call these agreements Publish \& Read.)

3. The third kind is the Pay-as-you-publish model which means that the costs for APCs are centralised and the institutions in the agreement do not have to pay a fixed amount in advance for a specific number of publications. This model would not include reading costs (Pieper \& Geschuhn, 2016).

Springer Compact is a Read \& Publish agreement. Funders call for agreements where publishers further commit to transforming their business model from subscription-based to OA, to eventually leave hybrid OA behind and have a publishing landscape consisting only of fully OA venues (cOAlition S, 2018). Such agreements are called transformative agreements $\left(E^{2} \mathrm{CC}^{3}\right)(\mathrm{ESAC}$, 2018). We are not aware of any truly transformative agreements running, in the sense that no agreement has yet included a plan of how and when the full transformation into an OA business model will take place.

\subsection{The Development of Transformative Agreements}

From a library consortia point of view, transformative agreements are signed with the purpose to accelerate the transition to an OA publishing system, at a reasonable cost, with increased transparency and more efficient administration of the OA workflow. Two developments have been important in leading up to the wish for transformative agreements in Sweden:

First, the rise of Open Science. European recommendations (European Commission, 2012) and a Swedish national proposal (Swedish Research Council, 2015) support a development towards Open Science, where all types of publicly funded research output are available to the public. Consequently, Bibsam strives to sign agreements that support and accelerate this transition.

Second, regardless of the business model, there is an increased need to monitor total costs and to ensure that tax money is well spent. The development of OA, including recommendations and mandates, has led researchers to pay largely unknown amounts of APCs to publish OA in hybrid journals 
over the past years. At the same time, publishers keep charging universities subscription fees to access subscription and hybrid journals. This has been referred to as "double dipping". The APCs paid by researchers or their institutions have proved difficult to monitor, which benefits publishers. It is in licensees' interest to sign agreements that control OA expenditure and total costs. In addition, the situation where researchers spend time on administrative chores related to individual APCs (applying for OA funding, administering APC payments) is an inefficient use of their time. There is a need for an improved workflow for OA publishing (Geschuhn \& Stone, 2017; Pinhasi, Blechl, Kromp, \& Schubert, 2018).

Library consortia who negotiate with publishers (in Europe mainly) increasingly demand OA parameters in publisher agreements, in line with research policies and the needs of academic institutions. Based on feedback from library consortia, publishers have developed new agreement models. Publisher agreements are frequently renegotiated, which offers constant possibilities for progress and evolution. Geschuhn \& Stone (2017) suggest that library consortia and research institutions should seize the current moment of transition in the academic publishing industry and influence publishers to improve their services, both to researchers and institutions. They encourage library consortia and research institutions to proactively engage to include metadata standards and improved institutional workflows into negotiations, to make the most out of available technical solutions and make publishers better cater to OA publishing. According to a recent survey from the European University Association (EUA), more and more university and library representatives are in fact getting involved in negotiations with academic publishers (Morais, Bauer, \& Borrell-Damián, 2018), which could be a sign of such engagement.

\section{Aim and Research Questions}

Several initiatives and signed agreements over the past years have pointed towards offset of costs from subscription to publishing fees as a way towards transforming the publishing of scholarly work into OA. There is often an emphasis on these agreements being pilots, indicating a tentative, temporary status. However, few studies so far have looked closely at the effects of such agreements for the institutions that enter into them. In this study, we aim to show the consequences and effects of Read \& Publish agreements 
by investigating one such agreement closely. We do this by addressing the following three questions:

RQ 1: What have the effects of Springer Compact been in Sweden with regards to costs, publication outcomes, administration and researchers' views and practices?

RQ 2: How does the Swedish agreement compare to other Read and Publish agreements signed with Springer Nature?

RQ 3: What advantages and risks can be identified with this type of agreement?

The findings reported here are a summary of findings made in a two-year evaluation project (Aldberg, Francke, Kronman, Olsson, \& Willén, 2017; Aldberg, et al., 2018; Franke, Kronman, Neidenmark, \& Willén, 2017; Francke, Lindelöw, \& Olsson, 2018). The results relating to RQ 1 and 2 are reported in the results section while RQ 3 is discussed in the light of these results in the discussion section.

\section{Method}

This evaluation is based on data from the publisher, the Swedish publication database Swepub ${ }^{4}$, and Open $\mathrm{APC}^{5}$ initiative. Furthermore, surveys were conducted with administrators and corresponding authors. A comparison was conducted with other Springer Compact agreements based on document studies of published reports and blog posts, and Springer Compact agreements available to the group as well as information from the Springer Nature website.

We collected survey data on the administration of publishing with the agreement from Swedish administrators $(n=16)$ from the 40 participating institutions that initially signed Springer Compact (29 HEIs and 11 research institutes or government agencies). The response rate among the administrators was $40 \%$.

With the help of the administrators, we also collected survey data on researcher attitudes and practices with regards to Springer Compact from corresponding authors (Francke \& Neidenmark, 2018). The survey was open 
to corresponding authors who published with Springer Compact between January 2017 and mid-June $2018(n=375)$. The response rate was $17 \%$. We have received responses from corresponding authors from 19 HEIs and two government agencies, including 13 out of the 14 most publishing institutions. We lack corresponding author responses from 19 of the participating institutions (10 HEIs and 9 research institutes or government agencies). While some institutions did not publish at all, we also believe that not all corresponding authors got an invitation to participate. Fourteen of the 19 missing organisations were institutions that published less than 19 articles with Springer in 2015. The survey contained both closed and open-ended questions.

Publication data was analysed too. Survey results have been analysed with descriptive statistics and by thematic analysis of open-ended questions.

To put the Swedish agreement in context, we compiled an overview of existing Springer Compact agreements. For the sake of comparison, we calculated the (rough) cost increases for signing Springer Compact agreements in Sweden, the Netherlands and the UK.

\section{Results}

In the following, we present an overview of Springer Nature's Read \& Publish agreements, Springer Compact, in Sweden and in other countries, and the effects of Springer Compact on the economy, publication outcome, administration and researchers' attitudes and practices in Sweden.

\subsection{Springer Compact}

The Netherlands, the United Kingdom, Austria, the Max Planck Society in Germany and, more recently, Finland, Hungary, Poland and Qatar, have signed Read \& Publish agreements with Springer Nature, similar to the Swedish one. In this section, we provide an overview of Springer Nature's Springer Compact agreements. The Hungarian, Polish and Qatari agreements were signed after the overview was made and are therefore omitted below. 


\subsubsection{Sweden}

In Sweden, 40 (later 42) Swedish institutions signed on for Springer Compact (2016-07-01-2018-12-31), negotiated through the Bibsam consortium. The agreement was signed as a pilot with the aim to increase OA, to move towards pay-to-publish and to increase cost transparency. By centralising publishing costs, it aimed to provide transparency and an overview of OA expenditure. Another desired effect was to improve the administrative workflow surrounding OA publishing. Wilhelm Widmark (director of Stockholm University library and head of the Bibsam steering committee), stated that "the purpose of the pilot is to gather experience by trying new processes and workflows for open access publishing" (National Library of Sweden, 2016).

The Swedish agreement covered OA publishing in Springer's 1,705 hybrid journals (called Springer Open Choice journals) and the reading of 2,110 of the e-journals accessed on the SpringerLink platform (Springer). Important to note is that the agreement did not cover fully OA journals in Springer Natures portfolio. The agreement covered the OA publishing of Original papers, Review papers, Brief communications, and Continuing education. There was no possibility for Swedish researchers to opt-out from publishing OA in Springer Compact.

According to the agreement, the publication of up to 4,162 articles ${ }^{6}$ by Swedish corresponding authors from the participating institutions was covered. The cost was based on a cost of 2,200 € per article (the current list price of Springer Open Choice journals), in addition to a reading fee which was lower than the previous subscription fee. To be eligible for publication within the agreement, the corresponding author of an article had to be associated with one of the participating institutions. The reduced subscription fee should be viewed as a condition for Bibsam to agree to the APC list price of 2,200 € for the articles. This is where the Swedish offset lies. See Table 1, for a comparison of the fees for 2015 and for an average year of the Springer Compact agreement.

The agreement ended 2018-12-31 and the negotiating parties agreed only at the last minute on the terms of a renewed agreement. All Swedish participating institutions renewed their agreement and an additional four joined for the term 2019-01-01-2021-31-12. 
Table 1. Springer Nature's Swedish publishing fee, reading fee, total cost and expected number of OA articles in hybrid journals: 2015 (the year before Springer Compact), and an average year of the Springer Compact agreement (2016-18, 2.5 years). The Springer Compact figures in this table are based on the 40 participating institutions that signed the agreement in 2016. Currently, 42 institutions participate.

\begin{tabular}{llll}
\hline & Tot cost 2015 $(€)$ & SC total 2016-18 $(€)$ & SC agreement avg year $(€)$ \\
\hline Publishing fee* $^{*}$ & & $9,156,400$ & $3,662,560$ \\
Subscr/Reading fee & $2,276,728$ & $1,313,273$ & 525,309 \\
Total & $2,276,728$ & $10,469,673$ & $4,187,869$ \\
Expected \# of articles & & 4,162 & 1,665 \\
\hline
\end{tabular}

*In 2015 Swedish researchers paid 345,400 € in APC. In Springer Compact, the publishing fee equals the list price APC $(2,200 €)$ times the pre-paid number of OA articles per year.

\subsubsection{Springer Compact in Other Countries}

Up until 2018, Springer Nature had signed Read \& Publish agreements with the following countries: the Netherlands, the UK, Sweden, Austria, the Max-Planck Society in Germany and Finland (Table 2). The comparison of agreements across countries was in some cases hindered or complicated by non-disclosure clauses. The comparison was further complicated by a number of factors, such as the differences in the number of participating institutions, size of portfolio subscriptions, size of prior agreements, size of the research community, and currency fluctuations. With these uncertainties in mind, we present the overview below.

Table 2 lists general information for the six agreements that were in place in 2018. The lengths of the agreements were between 2 and 3.25 years, cover OA publishing in 1,600-1,900 journals and reading rights to 2,000-2,500 journals. The British had issues with researchers choosing to opt-out from publishing $\mathrm{OA}$, and several countries have thus restricted that possibility. All agreements except the Max Planck Society's included the same article types: Original papers, Review papers, Brief communications, and Continuing education. The Max Planck Society only included Original papers and Review papers.

As the Netherlands have shared their agreements publicly and the UK have published reports on their agreement, these countries will be subject to further comparison to Sweden below. 


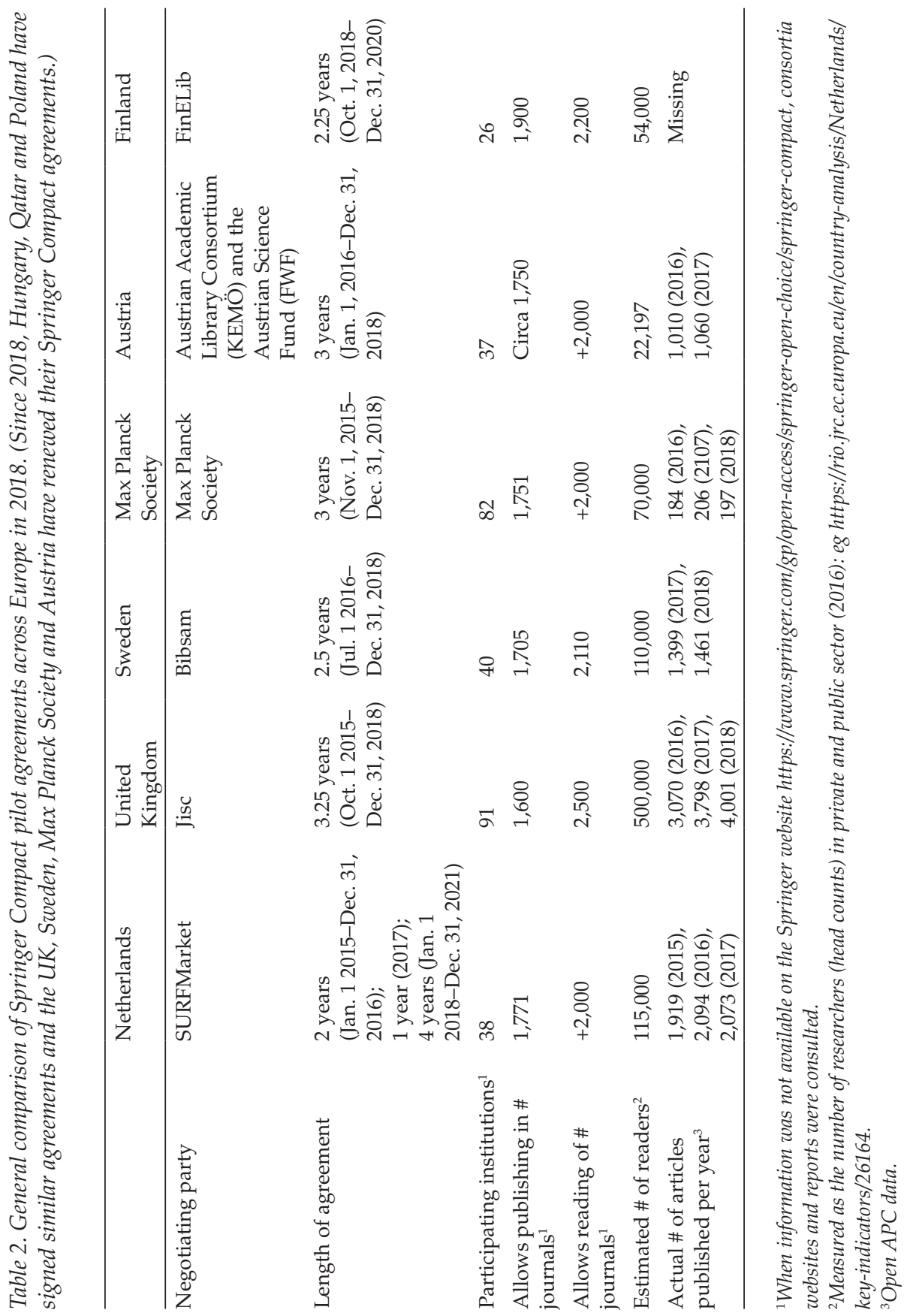




\subsubsection{The Netherlands}

The Dutch were the first to sign Springer Compact with Springer Nature (201501-01 to 2016-12-31). That agreement has been renewed twice, first by a year and then by another four years (2018-01-01 to 2021-12-31) (SURFmarket, n.d.). Being first has probably had a positive impact on the terms of the Dutch agreement. In 2014 (before Springer Compact), the Dutch paid Springer 2,939,929 $€$ in subscription fees (VSNU, 2017, Graphic 2). In addition, they spent an unknown amount on hybrid OA-publishing with Springer Nature that same year. In 2016, the Dutch paid Springer Nature 2,850,197 € (the average yearly spent between 2015-01-01 and 2016-12-31; Springer Compact Agreement Netherlands (1.2015-12.2016), 2017). The transition from a subscription-based model to OA was therefore achieved without any cost increase, or even with a cost decrease, in the Netherlands. The current agreement costs 3,040,620 € the first year and then has a $3.5 \%$ yearly increase. This is only a slight cost increase compared to the first agreement. Dutch authors are allowed to publish 2,080 articles per year within the most recent agreement. They have received a 25 $\%$ discount on about half of these articles $(1,010)$ and pay the list price for the remaining half (1,070 articles) (Openaccess.nl, 2018, p 84). Additionally, 155 new hybrid titles to publish in and 250 more titles to read were added (Openaccess.nl, 2018). The Dutch have consistently published their agreements online; to our understanding without repercussions.

Given that the Netherlands and Sweden are two countries similar in size with respect to the researcher population (Table 2), the countries' costs for Springer Compact, for roughly the same product, ought to be roughly the same.

\subsubsection{The United Kingdom}

The British Springer Compact agreement ran from 2015-10-01 to 2018-12-31. The cost for unlimited hybrid OA publishing in the British agreement was based on their 2014 hybrid OA article spend (Lawson, 2017a). In 2015, British institutions spent 8,759,854 $£$ on subscriptions (Lawson, 2017b) and 1,699,722 $€$ on hybrid OA-publishing with Springer Nature (Open APC Initiative, n.d.). That is, $8,057,974 €$, based on the average yearly exchange rate for 2015 of 0.72584 .

In 2016, the total paid by the British institutions was 9,897,706 $£$ (Lawson, 2017b). This equals 8,110,972 $€$, based on the average yearly exchange rate for 2016 of 0.81948 . This meant that the British only paid a smaller price increase $(52,998 €)$ for swapping from a subscription-based model to the Read \& Publish-model. 
The British have an almost five times larger research community than the Netherlands and Sweden but only published about 2 times as many OA publications as the Netherlands and less than 3 times as many as Sweden per year (Table 2). This is partly explained by the fact that many of the British corresponding authors in 2016 chose to opt-out from publishing OA (20\%) or published in the non-hybrid journals covered in the agreement (23\%) (Marques, 2017).

The British agreement (as well as the Austrian and the German) came to an end on 2018-12-31 and was renegotiated during 2018.

\subsection{Effects of Springer Compact in Sweden on Economy}

In this section, we specify the economic effects of Springer Compact on the national and the institutional level. Since Springer Compact only covers journals on the SpringerLink platform, it is also interesting to examine publication patterns of Swedish institutions in Springer Nature's total journal portfolio (i.e. fully OA journals and Nature journals), and not just those included in Springer Compact (hybrid journals from Springer).

\subsubsection{National Level - Economy and Publication Output}

At the national level, we present the cost for transitioning to OA with Springer Nature for Sweden and the cost of the oversize in the agreement. Before the signing of Springer Compact, approximately $12-13 \%$ of the publications by Swedish corresponding authors in the journals covered by Springer Compact was OA. This has to be compared with the almost $100 \%$ OA published within Springer Compact.

\subsubsection{Cost of Transitioning to OA with Springer Nature}

To be able to compare Springer Compact to the previous Swedish agreement with Springer Nature, and to the agreements of other countries, we calculated the cost for transitioning from a subscription-based model to the Read \& Publish model.

Table 3 summarises the cost and division of the Swedish Springer Compact agreement: 10,469,673 € for the two-and-a-half-year period July 2016-December 2018, divided between a publishing fee $(87 \%$ of the total cost 
Table 3. Average costs per year 2016-2018, with and without Springer Compact (SC). Without SC V1 and V2 are hypothetical costs, had Springer Compact not been signed. V1 is based on the number of hybrid OA articles published in 2013-2016, assuming hybrid OA publishing with Springer Nature will increase. V2 makes a more conservative estimate.

\begin{tabular}{llll}
\hline & An average year & & \\
\cline { 2 - 4 } & Without SC V1 & Without SC V2 & With SC \\
\hline Estimated \# of publications & 235 & 158 & 1665 \\
Subscription/Reading fee $(€)$ & $2,430,295$ & $2,430,295$ & 525,309 \\
Publishing fee $(€)$ & 515,680 & 348,229 & $3,662,560$ \\
Total $(€)$ & $2,946,855$ & $2,778,524$ & $4,187,869$ \\
\hline
\end{tabular}

and based on the APC list price) and a reading fee (13\% of the total cost). By adding a $3 \%$ yearly price increase to the 2015 subscription fee (Table 2) we can calculate an average hypothetical cost of 2016-2018 per year, had Springer Compact never been signed and Swedish institutions continued to pay subscription fees. Table 3 displays the results of this calculation. When calculating the possible hybrid fees Swedish institutions would have paid without Springer Compact, two approaches have been used: V1 predicts a yearly increase in the number of published hybrid OA articles with Springer Nature, based on published articles in 2013-2016. The other approach, V2, calculates an average value based on the articles published in 2013-2016, making a more conservative estimate of the future of hybrid publishing. Since the cost of Springer Compact was unevenly distributed between years, an average cost per year has been calculated for both the Springer Compact agreement and the hypothetical costs without the Springer Compact agreement. This shows that the Springer Compact agreement was $42 \%$ costlier than if Swedish institutions would have carried on with the former agreement and published according to V1, and $51 \%$ costlier using the more conservative estimate of V2. This equals $1,241,014 €$ or 1,409,345 $€$. Given that hybrid publishing has been on the rise in recent years, V1 may be the more reasonable estimate. The costincrease was subsidised by the Swedish Research Council and the National Library of Sweden (11.6 million SEK, about 1.1 million $€$ ).

\subsubsection{Cost of Oversize}

The number of articles Swedish researchers were expected to publish during the agreement turned out to be an overestimation compared with the actual 
outcome. The number of articles actually published amounted to 3388, which equals $81 \%$ of the expected number. Pre-paid and not published articles will not be reimbursed if not published by the end of the agreement. The value of the non-published articles amounted to $1,713,800 €$.

\subsubsection{Hybrid Journals vs. Fully OA Journals by Springer Nature}

A future concern is the growth rate of the scholarly publishing universe. The subscription model has seen cost increases in the range of $3 \%$ over time, as more content is constantly added to already big deals. As researchers all over the world face the pressure to publish in order to enhance their careers, the current system may never be satisfied. There is also quite a new trend to publish everything that passes peer review in so-called mega journals, as opposed to earlier selective processes where new or central ideas were selected, leading to high rejection rates.

Table 4 presents the number of publications in the Springer Nature portfolio with corresponding authors from the Bibsam organisations. Springer Open Choice (covered by Springer Compact) is the largest outlet for Bibsam authors, followed by BMC (BioMed Central), with fully OA journals only. Many of the outlets show growth over the presented years, and especially Nature gold journal articles are growing fast. This is mainly due to the journals Scientific Reports (76\% of articles) and Nature Communications (18\% of articles). The fastest growing outlets in the portfolio of Springer Nature, where Swedish researchers show the largest increase in publishing, are thus not included in Springer Compact.

\subsubsection{Institutional Level - Economy and Publication Output}

In the Swedish Springer Compact agreement, the participating institutions paid a $3 \%$ raise on their 2015 subscription price plus a publishing fee based on their publishing in Springer hybrid journals in 2015 (6 levels, see report 3 for details). The rest of the agreement was, as mentioned, subsidised and therefore not paid for by participating institutions.

Table 5 shows the number of institutions on the different levels and their corresponding shares of the extra cost induced by Springer Compact. 
Table 4. Articles and reviews published by Bibsam corresponding authors with Springer Nature 2015-2017. The numbers are to be regarded as preliminary due to data quality.

\begin{tabular}{|c|c|c|c|}
\hline Springer Nature & 2015 & 2016 & 2017 \\
\hline \multicolumn{4}{|l|}{ BMC } \\
\hline gold (fully OA-journals) & $534^{2}$ & $590^{3}$ & $485^{3}$ \\
\hline \multicolumn{4}{|l|}{ Springer Open } \\
\hline gold (fully OA journals) & $71^{2}$ & $65^{2}$ & $92^{2}$ \\
\hline \multicolumn{4}{|l|}{ Open Choice/Compact } \\
\hline Subscription ${ }^{1}$ & $1,059^{2}$ & $\mathrm{NA}^{4}$ & $\mathrm{NA}^{4}$ \\
\hline hybrids & $157^{2}$ & $1,056^{2}$ & $1,399^{2}$ \\
\hline \multicolumn{4}{|l|}{ Nature } \\
\hline Subscription $^{1}$ & $83^{3}$ & $95^{3}$ & $120^{3}$ \\
\hline hybrids & $54^{3}$ & $48^{3}$ & $17^{3}$ \\
\hline gold (fully OA journals) & $177^{3}$ & $324^{3}$ & $368^{3}$ \\
\hline \multicolumn{4}{|l|}{ Palgrave McMillan } \\
\hline Subscription ${ }^{1}$ & $24^{3}$ & $22^{3}$ & $22^{3}$ \\
\hline hybrids & $7^{3}$ & $2^{3}$ & $2^{3}$ \\
\hline
\end{tabular}

${ }^{1}$ Hybrid option may be available.

${ }^{2}$ Data from Springer Nature.

${ }^{3}$ Data from Swepub.

${ }^{4}$ No data is available on the number of publications published in journals that do not offer hybrid $O A$. If there is a hybrid OA option, Swedish corresponding authors will automatically publish hybrid $O A$ in accordance with the SC agreement.

Table 5. The original number of institutions on the different levels and their share of the articles in 2015 and extra cost in 2016.

\begin{tabular}{llll}
\hline Level & \# of institutions & $\begin{array}{l}\text { Share of articles } \\
2015(\%)\end{array}$ & $\begin{array}{l}\text { Share of extra cost } \\
\text { induced by Springer } \\
\text { Compact in 2016 }(\%)\end{array}$ \\
\hline 1 & 17 & 3 & 6 \\
2 & 9 & 6 & 10 \\
3 & 1 & 1 & 3 \\
4 & 3 & 6 & 11 \\
5 & 4 & 24 & 20 \\
6 & 6 & 60 & 50 \\
Total & 40 & 100 & 100 \\
\hline
\end{tabular}


In Table 6 we see the cost in 2017 for each of the institutions in the agreement. The extra cost induced by the Springer Compact agreement is shown in two different ways: as what the institutions paid in 2017, taking the National Library and the Swedish Research Council subsidising into account, and what they would have paid without this support. Table 6 also shows the number of publications in 2017. Three of the forty institutions that initially signed on for Springer Compact did not publish at all in the journals covered by the agreement. (Neither did the two institutions that joined later during the term.)

To evaluate the current cost distribution model for institutions, the extra fee of the Springer Compact agreement has been divided by the number of articles published by that institution (not to be confounded with an APC cost as the distribution model is based on earlier subscription fees). Some institutions have published above expected for their level (see Tables 5 and 6 ) in 2017, whereas others have published below their level. The former group ends up with a low cost per publication, whereas the institutions in the latter group (primarily on levels 2 and 3) are those that have a higher cost per publication. This is also the case for the institutions on level 1 with very few publications. This means that smaller and non-publishing institutions have helped finance the transition from pay-to-read to pay-to-publish. One argument for this could be that they will have reduced or no subscription costs in an OA future. The shares (Table 5) were somewhat altered in 2018 when two more institutions joined the agreement. The updated figures for 2018 would require an additional table, therefore the figures in Table 6 are based only on data from 2017.

\subsubsection{Disrupted Budgets}

One challenge with Springer Compact was to share costs without disrupting current institutional/library budgets. Institutions used to pay for subscriptions based primarily on their expected number of readers. The shift towards paying for publishing presents challenges at multiple levels (institutional, national or global), as there will be more potential readers than writers. To this can be added the fact that several of the institutions subscribing today publish rarely, or not at all. Can they be expected to share the publishing costs? For the institutions that do publish, offsetting raises other concerns: the library budgets of today are planned for subscription costs, whereas the Springer Compact agreement also includes APC costs that are currently paid 


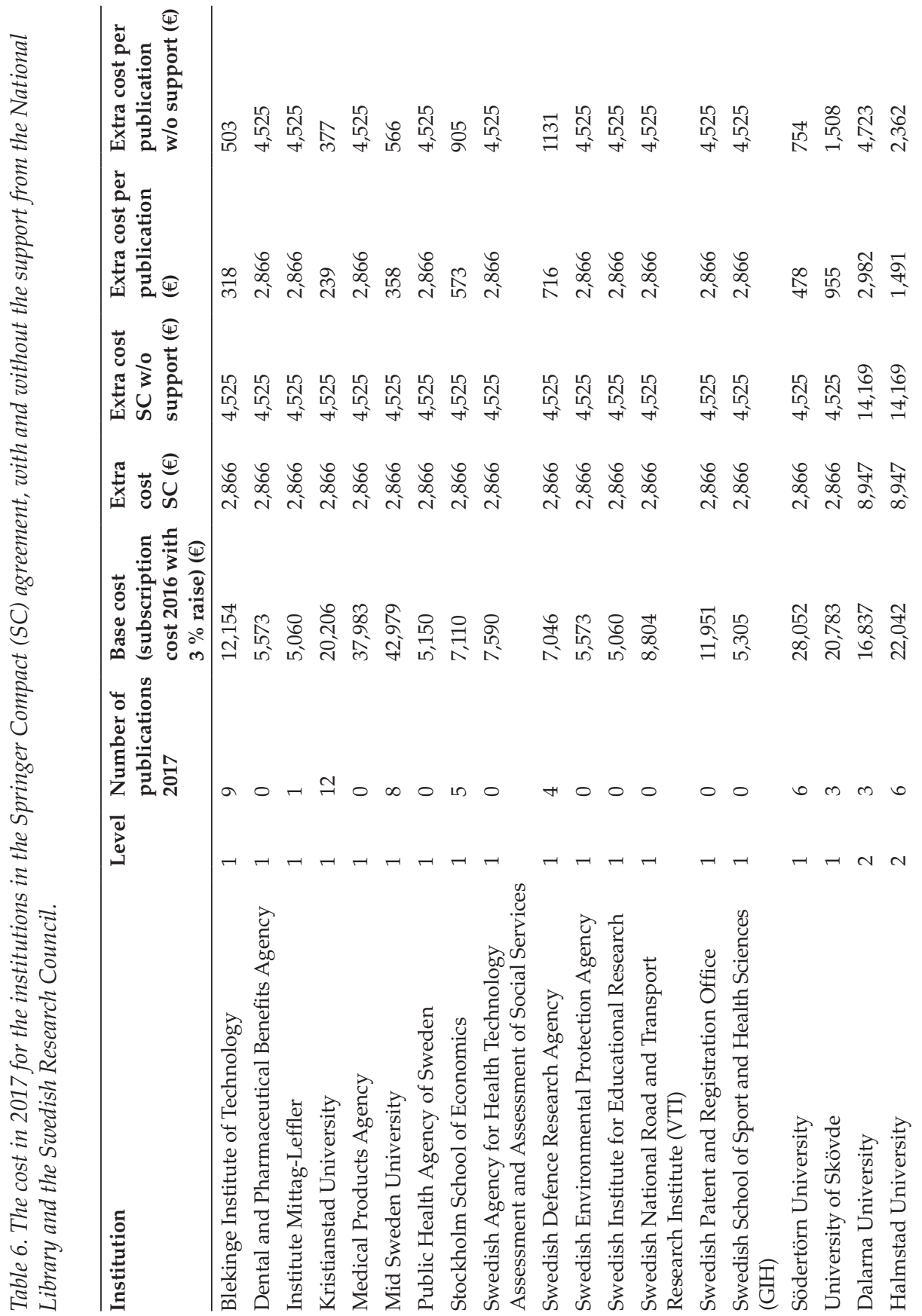




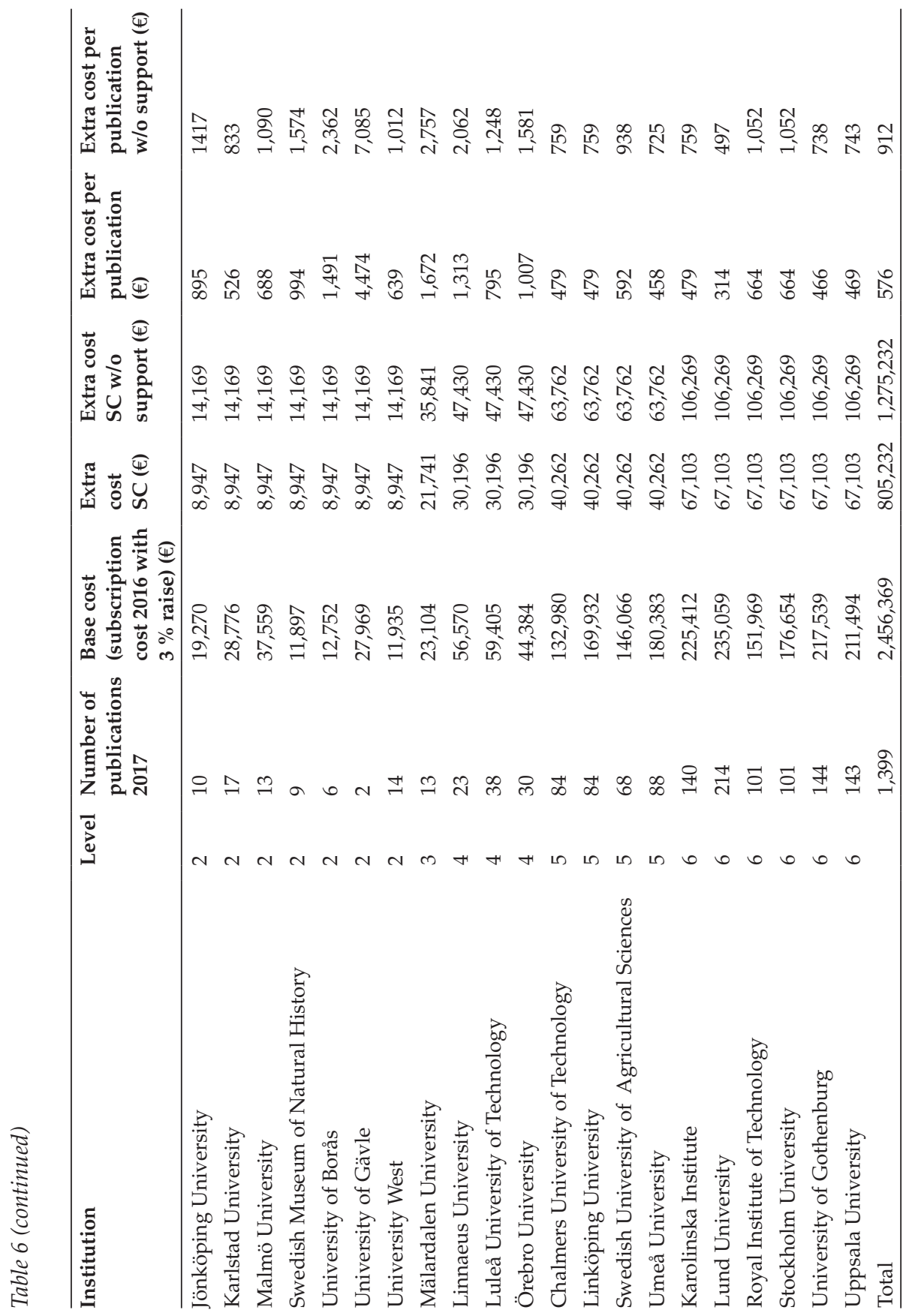


as part of funder grants, with faculty funds or with a centralised OA fund at the university.

We illustrate this shift with a hypothetical distribution in Figure 1. The x-axis shows the subscription costs that the institutions actually paid in 2015. The $y$-axis shows a hypothetical cost, calculated by dividing the total subscription

Fig. 1: Distribution of costs in a publish-based model vs. a subscription-based model. For the purpose of comparison, the total cost of subscriptions ( $x$-axis) has been redistributed based on the average number of articles per year in the Springer Compact agreement (y-axis). Institutions above the line would pay more for publishing whereas those below the line would pay less. Lund University (lu) and the Swedish Patent and Registration Office (pro) serve as examples.

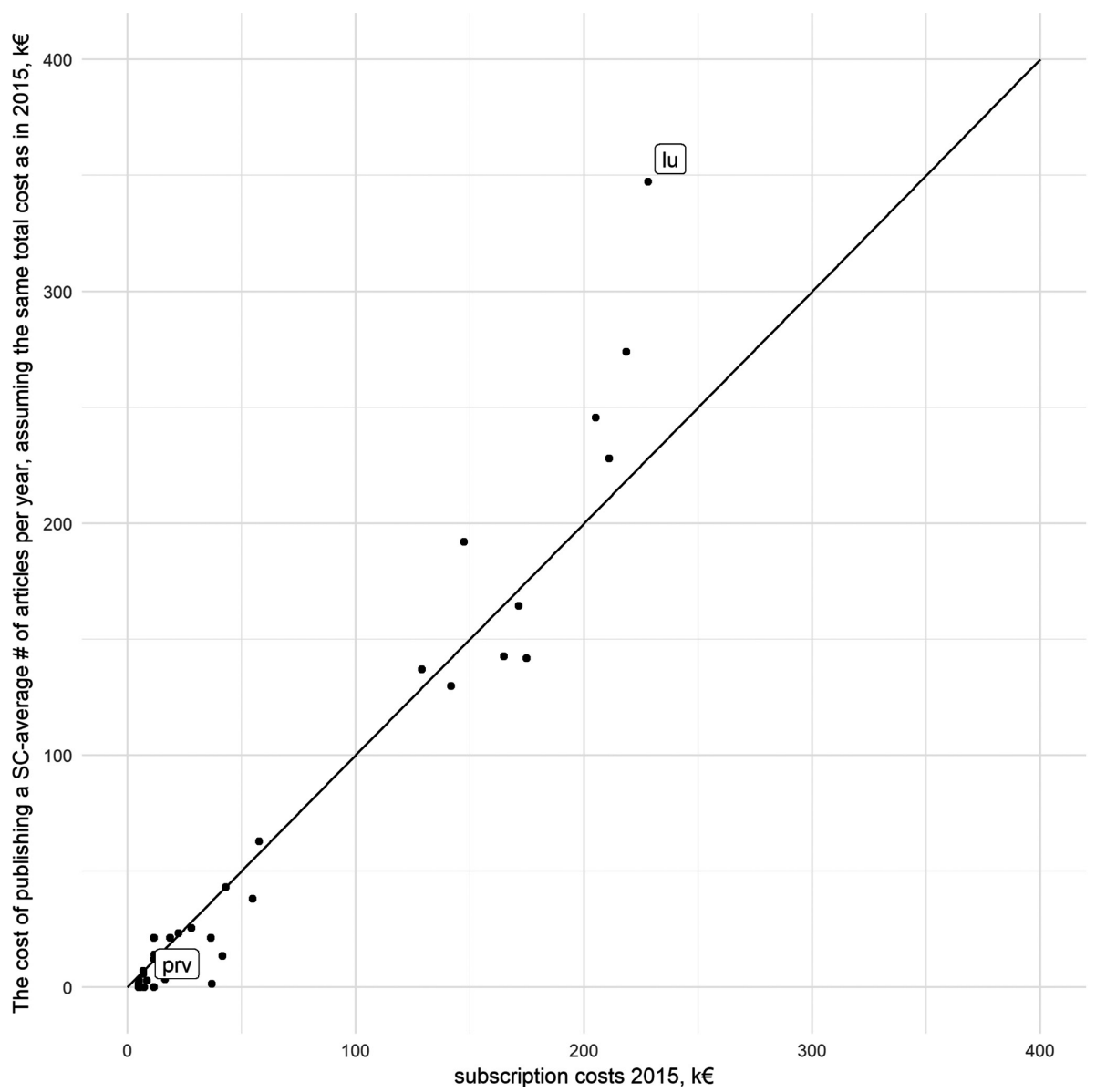


cost of 2015 by an average number of articles published per year and institution in the Springer Compact agreement. The average number of articles per year in the Springer Compact agreement is based on the whole agreement period. Ideally, this average would have to be based on more years to give a more stable view of article output. The institutions above the line would pay more and the ones below would pay less for publishing than for subscribing. The figure shows that several institutions wouldn't pay at all (those who don't publish) whereas the four largest institutions would pay considerably more in a publish-based model than a subscription-based model, given that the current costs levels are sustained. Without a redistribution of costs between institutions, non-publishing institutions would benefit from the model where you pay to publish, while publishing institutions would benefit from the subscription model where costs are more shared between institutions.

\subsection{Effects of Springer Compact on Administration}

This section reports the results of a survey distributed to the administrative staff handling the Springer Compact at each participating institution. Administrative staff representing 16 of the 40 participating institutions in Springer Compact chose to respond to a survey about their workload. The overall impression was that the Article Approval Service (AAS) worked well for those who administered Springer Compact. The respondents deemed the system easy and efficient. Most respondents (13 of 16) stated that they spent less than an hour of work on Springer Compact per month. No administrator spent more than 3 hours (work for this evaluation included). When the author affiliation is unequivocal, it takes less than two minutes to approve the article. This workload is to be compared with the effort it would otherwise take each researcher to pay their separate billing, should they choose to publish OA.

Rejections due to ineligibility were fewer than $5 \%$. The main reason for not approving an article was that the corresponding author lacked adequate affiliation. Authors changing affiliation during the publishing process did not cause many problems. Only a few administrators have had to address instances where authors contest rejection. The issue at hand was that journals sometimes used a different terminology when naming their article types than Springer Nature does.

The administrators' workload varied. In 2017 the administrators approved three articles per month on average (ranging from 0 to 27). 
Despite the benefits of the AAS, being part of Springer Nature's standard workflow also had disadvantages. Since the workflow was initially set up to serve publishing in subscription journals, it proved difficult to make small, but necessary, adjustments to accommodate OA authors. As an example, Springer Nature had standard e-mails sent out to all authors and in some instances, the information in them was impossible to alter, even if the information was inadequate and misleading. According to the survey responses of the Swedish corresponding authors (see next section), $81 \%$ were unfamiliar with CC-BY licenses after having published through Springer Compact (i.e. CC-BY). Hence, an important educational opportunity was missed, where researchers could have been informed about licensing with the help of Springer Nature and Springer Compact. Springer Nature was asked to include clearer information on the licensing in the AAS, but they were not able to adjust information to suit OA publishing in all parts of their workflow.

To make sure Springer Nature fulfilled their end of their agreement it turned out necessary to follow up each paragraph of the agreement in detail. In particular, it was important to engage with Springer Nature in the wording of all texts on OA. When authors are informed about their accepted articles it is crucial that they receive the correct information on their published article's OA license (https://creativecommons.org/licenses/by/4.0/), its OA funding, and not to confound OA with Springer Nature's own sharing initiative, "SharedIt". Authors should be encouraged to link to their publication's original digital object identifier (DOI) when sharing it. It is also desirable to make the license visible in the publication's first-page header.

\subsection{Researchers' Attitudes and Practices}

This section reports the conclusions drawn from the results of a survey sent out to corresponding authors in Springer Compact.

\subsubsection{Springer Compact Agreement and OA Publishing}

The main reasons for submitting an article to a particular journal (multiple responses possible) were stated as the journal being the best topical match $(76 \%)$, having a high Journal Impact Factor $(25 \%)$, a good editorial process 
(17\%) and offering the possibility for open access publishing (17\%). The responses show that although OA publishing was not one of the most important reasons for submitting an article to a journal, it was still a feature that authors appreciated, and $17 \%$ mentioned it as one reason for choosing a particular journal. At the same time, authors were overall positive towards the idea of more agreements such as Springer Compact. Among free-text answers where respondents were encouraged to elaborate on their view on these agreements, many only responded with an expression of appreciation. Some mentioned certain researchers' difficulty to fund APCs (for instance doctoral students), along with benefits brought by OA for visibility and impact. The ease of handling the process on the part of the author, which comes with Springer's AAS, was mentioned by some. Although most respondents were OA advocates, some did voice concern. These concerns covered questions about the cost of the agreement, about the costs involved in scientific publishing in general, and a desire for non-commercial OA alternatives to be developed and supported.

Despite many of the respondents saying that they were very positive to OA publishing, only $39 \%$ reported that they would or would perhaps have paid for OA publishing of the article which was published through Springer Compact. This was about the same number of respondents (though not necessarily the same individuals) who said they had paid APCs on previous occasions and also about the same number who reported that their current research, or parts of it, was covered by an OA mandate. When asked about who the funder was, the Swedish Research Council was by far the most often mentioned funder, but another 31 public and private funders were noted, many in the medical and environmental areas.

\subsubsection{Alternative Models}

Although fewer than $1 \%$ of the respondents provided answers which opposed the move towards OA publishing, a number of respondents $(5 \%)$ would like to see a different route to OA. These respondents said they would like to see publishers provide OA at a more reasonable price than today, or advocated alternatives which are non-profit. Open repositories (possibly with a journal overlay), non-profit publishers, and university-run journals or publishing platforms were suggested. Some respondents also mentioned that 
OA through parallel publishing should be easier and that there should be more information about this option.

\subsubsection{Awareness of Creative Commons Licenses}

The publications covered by the Springer Compact agreement are published with the Creative Commons Attribution license CC-BY (Creative Commons, n.d.). The survey contained a question about whether or not the respondents were familiar with the CC-BY-license. As many as $81 \%$ of the respondents answered that they were not. With such a brief question, it was difficult to know if they knew the license under a different name, or how they interpreted 'familiar'. Regardless, given that a number of initiatives, including the Science Europe cOAlition S (2018) and the Swedish "Proposal for national guidelines for open access to scientific information" (Swedish Research Council, 2015), expect publications to have some form of Creative Commons license, the low number of respondents who claimed familiarity with the license is worrying. There is a risk that authors are as uninformed about the conditions under which their publications are made available through OA, as they were when their copyright was transferred to publishers.

\subsubsection{Support from the University and the University Library}

Most authors (73 \%) did not know about the Springer Compact agreement before they submitted to the Springer journal. Rather, several authors comment that OA publishing came as a pleasant surprise during the publishing process. It was not surprising, then, that $34 \%$ of respondents mentioned "more information" when asked how their university can better support them in OA publishing. As seen above, such information could include copyright issues.

The support most authors said they would like the university to provide, however, was financial and administrative. As many as $44 \%$ stated in freetext answers about university support that they would like the university to ensure that there is funding for OA publishing and to handle the payment. This may be in the form of transformative agreements, OA funds or other solutions. Such funding needs to be predictable and easy to secure. 


\section{Discussion}

After having reported on Springer Compact in Sweden, the Netherlands and the UK (RQ 1 and 2), we conclude by discussing the advantages and risks with these agreements which have been identified during the course of the study (RQ 3). The discussion is structured so that advantages and risks are discussed in relation to economy and transformation, administration and researcher attitudes.

\subsection{Economy and Transformation}

According to Pinfield (personal communication, 2018, October 10), policymaking for OA entails the balancing of three priorities: 1) achieve OA quickly, 2) transform the system into one where you pay to publish rather than to read, and 3) reduce costs. It is very difficult to make all three the main priority. When applying Pinfield's priorities for policy-making onto Springer Compact, the Swedish agreement is a success in one of the three ways: in achieving OA quickly, particularly if authors are not allowed to opt-out of publishing OA. In Sweden, about 12-13\% of the publishing in the journals covered by Springer Compact was OA before the agreement, compared to nearly $100 \%$ OA since the agreement was signed.

As for the second priority, on transforming the system, detailed information on when and how to complete the transformation from subscription-based to OA publishing was lacking in the Swedish agreement. Future agreements need to specify within what timeframes the transition to pay-to-publish must take place in order to move towards full transformation. ESAC (2018), Jisc (2018) and cOAlition S (2018) all emphasise the necessity of transformative agreements being explicitly transitional. They also stress that the financial support for hybrid must be withdrawn, to avoid supporting hybrid OA at the expense of fully OA and larger publishers at the expense of smaller. We recommended for the Swedish renegotiations that fully OA journals should be included in Springer Compact. For consortia, being able to negotiate for the whole portfolio will help in seeing the full picture, and try to forecast the publication patterns of the future.

The third of Pinfield's priorities, to reduce costs, is deemed least prioritised in the Swedish Springer Compact since costs were substantially augmented 
compared to the previous, traditional agreement. In the 2015 paper Disrupting the subscription journals' business model for the necessary large-scale transformation to open access (Schimmer, Geschuhn, \& Vogler, 2015), the concept of "enough money in the system" was introduced. The paper outlines a global transformation from a subscription-based model to an OA business model financed by the money already in the system. The Swedish Springer Compact agreement does not meet this criterion. Instead, by using a baseline that comprises both subscription costs and APCs paid outside library budgets in 2015, and thus giving a cost increase of $42 \%$, it adds more money to the system. In part, the cost increase can be attributed to the oversize of the agreement: 779 of the pre-paid articles were not used. Still, it seems that transformative agreements can be cost neutral (Science Europe, 2016), of which the Dutch and British Springer Compact agreements are (near) examples. The Dutch were allowed unlimited publishing in their first agreement, without cost increase. The British were allowed unlimited publishing in their first agreement for the sum they had paid for OA publishing in the year leading up to Springer Compact and they had only a slight increase of total costs. Paying institutions saw OA as a potential for reduced costs: Those who did not publish saw the possibility to not have to pay subscriptions in an OA-future. Those who did publish learnt that there was enough money in the system (Schimmer et al. 2015) and figured that big deals would result in discounts on APCs and thus reduce costs. However, Springer Nature has kept their income at the same (or higher) levels as in the subscription system. So far, neither reading nor publishing institutions have had cost reductions. Also, the number of readers seems to be substantially larger than the number of authors. If the current amounts paid are to be redistributed, the publishing institutions face an expensive future unless models of co-operation or redistribution of public funding are set in place. Coupled with the need for individual researchers to publish in order to enhance their careers and, as a result, a continued need for journals to publish in, it seems that costs will tend to rise considerably. The growth rate of authors of Swedish institutions publishing in fully OA journals like Scientific Reports and Nature Communications seems to affirm this. This also highlights the need to include fully $\mathrm{OA}$ in future agreements. In addition, it highlights the need for continued publication data collection and analyses. Preferably, collaboration on an international level would help to share methods and to find different publication patterns. This is important also because researchers tend to publish in international groups. Finally, the issue of flipping individual journals (from hybrid to $\mathrm{OA}$ ) is unresolved in Springer Compact. Library consortia should, if possible, seek collaboration to 
establish concrete flipping terms for journals, with Springer Nature and other publishers.

The issue of increased costs is not only a matter of handling tax money with care. Increased costs also risk maintaining or increasing injustices between researchers of unequal resources. An OA scholarly publishing system will help researchers, regardless of their institutions' financial resources, to access published research in the future. However, the ones lacking funds for OA publishing will not be able to contribute to it on the same terms as researchers in countries or at institutions with more ample resources. This is a perspective that needs to be taken into account when negotiating future business models for publishing, in order to avoid conserving or building new unjust systems for the future (see Haider, 2007).

The publication outcomes of this agreement showed the need for sharing risks between institutions and publishers. A model where a fixed number of articles come with the same list price for APC cost could be switched for a model where a forecasted amount of articles is widened to a span around this amount with a fixed price (a so-called corridor), or giving discounts on APCs above a certain publication amount. As stated above, the future of publishing looks bright within the current system, as researchers face the pressure to publish. The higher growth of Springer Nature OA journal articles by corresponding Bibsam authors may be a sign of the researchers' need to publish OA, and that mega journals, or similar journals with a prestigious name, could be a way for researchers to satisfy rising OA demands while sticking to the traditional career enhancement system of being judged by the publication channel. There are initiatives for changing the ways in which research output is evaluated, such as the DORA declaration, which may in time come to make the push both for the number of publications and for publishing in particular outlets less relevant.

As the transformation to an open access model can still be said to be at a beginning, it is interesting to see how the first Springer Compact agreements signed have affected the global level. INTACT ${ }^{7}$ has gathered data from the first parties signing Springer Compact. Currently, about $8 \%$ of the articles published in the Springer Open Choice journals are OA - a start which can be promising or frustrating depending on which OA stance you adopt. Out of this $8 \%$, the five original Springer Compact agreements, representing only a small part of the European research community, account for $52 \%$ 
(Broschinski, 2018). Analyses like these highlight, as mentioned before, the need for international collaboration in data gathering and analyses.

\subsection{Administration}

In this section, administrative issues pertaining to the workflow for publications as well as the administration of allocating costs between institutions at the consortium level are discussed.

\subsubsection{Publishing Workflow}

Springer Compact entailed a significant improvement in the workflow for OA publishing through the use of the article approval system (AAS). Despite its benefits, there were also issues of inflexibility in the article approval system. The workflow must allow for customised information to be sent out to authors of OA publications and not assume that authors publish non-OA as a default. Others have raised concerns along the same lines: that the existing workflows of the traditional publishers might not be able to cater to the needs of OA (Geschuhn \& Stone, 2017; Pinhasi et al., 2018). Continued international collaboration on the development of international standards, specified best practices, and optimised workflows are necessary to further improve and fit article approval systems to the needs of OA publishing. Identified viable solutions could be adopted by smaller or alternative publishers looking to establish new routines.

\subsubsection{Consortium Administration}

An administrative challenge at the consortium level of switching from a model where institutions pay to subscribe to a model where they pay to publish is reflected when trying to determine the costs of individual institutions within the consortium. What is fair? Today, university libraries handle subscriptions whereas publishing fees to a large degree are paid with money from grants or the researchers' departments. These separate funding routes could be pooled in order to facilitate administration and gain insight into total costs, for example when trying to keep track of hybrid fees. Gaining 
control over the money flows will not automatically help switch the system but would help reduce the financial pressure on individual researchers and libraries/institutions.

Another challenge is related to the system where you pay for an expected article output in advance and would be solved if the system was based on a pay-as-you publish system (i.e. no reading fee) like in fully OA journals. It could be argued that a fixed amount of articles tend to create a lock-in effect, maybe even pushing administrators to advertise for publishing in their outlets in order to meet the levels agreed on beforehand. Individual institutions gain reduced costs because of volume discounts and administration efficiency from being part of a consortium. It could be argued that publishing is more volatile than subscribing as authors may choose more freely where to publish whereas they often need to subscribe to all journals in order not to miss out on important research results. Thus volume discounts may not be as valuable for publishing as they were for subscribing. Administration efficiency, on the other hand, seems to be important also within a pay-asyou-publish-system as our survey demonstrated. If publishing fees could be handled by expert administrators on an aggregated level instead of individually by each researcher, time and money would be saved. Furthermore, joint negotiations with the publishers, possibly in collaboration between consortia globally, could contribute to predictable and sustainable costs for APCs.

A short-term recommendation for consortia would be to base tier calculations on several years of publishing output, as the one year-based tiers of the current Swedish agreement lead to some institutions gaining and others losing because they published more or less than expected (Table 4). Eventually, this could be combined with a system to roll over costs between years or institutions in order to balance costs. In a longer-term perspective, consortia may also have to rethink their value, as they were also constructed for a subscription-based-system. Will it be efficient to handle publishing fees at a national level, or would that be too far away from the researchers using the system?

\subsection{Researchers' Attitudes and Practices}

In Plan S, it is pointed out that the publishing researcher should not be the one responsible for paying APCs (cOAlition S, 2018). Yet, researchers often end up spending time and effort securing funding for APCs - or at least 
worry that it will be difficult to secure such funding. Agreements such as Springer Compact make the OA component of publishing effortless for the researcher. The survey with corresponding authors also shows that this is a highly appreciated feature among the respondents. They saw several benefits with publishing OA, but would not necessarily have valued these benefits high enough to try to secure funding for APCs if it was not part of the agreement. Thus, the ease with which OA publishing is achieved on the part of the author is an advantage of the agreement. The agreement, especially since it is based on hybrid publishing also allows researchers to continue publishing without changing their behaviour. They publish in the journals they are familiar with, whose publishing process they trust and whose reputation they consider beneficial to their career.

The associated risk is that the costs involved in publishing are not visible to researchers when publishing as part of this type of agreements. In this way, the business logic continues to be based on a model where the users of the product (researchers) are not the buyers of it (libraries, universities and funders), meaning that the conventional principle of supply and demand will be malfunctioning (Suber, 2012). Increasing costs for the universities for publishing is also a risk mentioned by a few of the respondents in the survey, as they see resources move from other parts of the research process to publishing. However, this does not necessarily lead the researchers toward transformative OA alternatives. The respondents reported that they would like to receive more information about Springer Compact and similar agreements, but also about other issues related to OA, such as help with finding good OA options for their publications. Some authors would like to see alternative OA models, primarily non-profit ones. We recommend institutions to be more active in informing their researchers about their existing OA publishing agreements and discounts. Also, researchers' knowledge of Creative Commons licenses was scarce. Resources should be directed towards informing researchers about copyright, and Creative Commons in particular.

\section{Conclusions}

In Sweden, Springer Compact was successful in that it generated a large increase in OA publishing (from an estimated 158 or 250 publications per year to approximately 1,400 per year). To transform the system for academic publishing and secure open access to scholarly publications such increases 
at a large scale are necessary. Springer Compact furthermore entailed a significant improvement in the workflow for OA publishing and centralised the OA expenditure. These factors, in combination with the guarantee to authors that they do not need to apply for APC funding, were the advantages of Springer Compact. The disadvantage with Springer Compact was its expensive business model and its risk of conserving the current system since it sustains hybrid OA without specifying how or when the full transition to an OA publishing system will be achieved. International initiatives by LIBER, ESAC, H2020 and cOAlition S are helpful for consortia to put further pressure on publishers to limit the future of hybrid OA and mitigate this risk. Finally, the Swedish Springer Compact was expensive. Smaller institutions have had increased costs that have been difficult to carry and that have infringed on other subscription funds. Yet, all of the Swedish participating institutions and an additional four signed on for a new term of Springer Compact (2019-01-01-2021-31-12) that did not substantially differ from the previous agreement. There is a risk with pilot agreements that they become more permanent than intended and have an anchoring effect on the agreements that follow. Before any new pilots are entered, it is advisable to know one's data and have the overall strategic arguments in line (not just the arguments for the particular pilot or agreement in question but its place in the overall strategy towards transforming the system). In the future, if publishers insist on maintaining their level of income, the few institutions that publish a lot will have a large increase in costs. If the model for Springer Compact is to be adopted by hybrid publishers, the total cost will be large for these institutions to carry.

\section{References}

Aldberg, H., Francke, H., Kronman, U., Olsson, L., \& Willén, N. (2017). Utvärdering av offset-avtal - delrapport 2: Springer Compact och Institute of Physics. Stockholm: National Library of Sweden. Retrieved October 15, 2019, from https://openaccess.blogg. kb.se/files/2017/09/Utva\%CC\%88rdering-av-offset-avtal-SC-och-IOP-delrapport-2. pdf.

Aldberg, H., Francke, H., Lindelöw, C. H., Kronman, U., Olsson, L., \& Willén, N. (2018, February). Evaluation of offset agreements - report 3: Springer Compact. Stockholm: National Library of Sweden. Retrieved from https://openaccess.blogg.kb.se/ files/2018/02/Evaluation of offset agreements SC Report 3.pdf. 
Broschinski, C. (2018). Springer Compact coverage analysis. [slides] Retrieved March 4, 2019 from https://www.ub.uni-bielefeld.de/ cbroschinski/presentations/ slidy/2019 0117 Workshop for OA data experts.xhtml\#(1).

cOAlition S. (2018). Guidance on the implementation of Plan S. Retrieved October 15, 2019 from https://www.coalition-s.org/wp-content/uploads/271118 cOAlitionS Guidance.pdf.

Creative Commons. (n.d.). Attribution 4.0 International (CC BY 4.0). Retrieved March 4, 2019 from https:// creativecommons.org/licenses/by/4.0/.

ESAC. (2018). On the effectiveness of APCs. Retrieved October 15, 2019 from http:// esac-initiative.org/wp-content/uploads/2018/07/esac apc workshopIII outcome report final.pdf.

European Commission. (2012). Commission recommendation of 17.7.2012 on access to and preservation of scientific information. Retrieved October 15, 2019, from http:/ /ec.europa.eu/research/science-society/document library/pdf 06/ recommendation-access-and-preservation-scientific-information en.pdf.

Franke, H., Kronman, U., Neidenmark, T., \& Willén, N. (2017). Utvärdering av Springer Compact - halvårsrapport 1. Stockholm: National Library of Sweden. Retrieved October 15, 2019, from https://openaccess.blogg.kb.se/files/2017/02/springer_compact evaluation report1.pdf.

Francke, H., Lindelöw, C. H., \& Olsson, L. (2018). Evaluation of offset agreements report 4: Springer Compact. Stockholm: National Library of Sweden. Retrieved October 15, 2019, from https://openaccess.blogg.kb.se/files/2018/10/Evaluation of offset agreements SC Report 4-20181008.pdf.

Francke, H., \& Neidenmark, T. (2018, July 12). Springer Compact evaluation - Researcher attitudes questionnaire on Springer Compact, Open Access publishing, and Open Access financing. [slides]. https://doi.org/10.6084/m9.figshare.7122545.v3.

Geschuhn, K., \& Stone, G. (2017). It's the workflows, stupid! What is required to make 'offsetting' work for the open access transition. Insights, 30(3), 103-114. https:// doi.org/10.1629/uksg.391.

Haider, J. (2007). Of the rich and the poor and other curious minds: On open access and development. ASLIB Proceedings 59(4/5), 449-461. https://doi. org $/ 10.1108 / 00012530710817636$.

Jisc. (2018). Requirements for transformative Open Access agreements: Accelerating the transition to immediate and worldwide Open Access. Retrieved October 15, 2019, from https://www.jisc-collections.ac.uk/Transformative-OA-Reqs/.

Lawson, S. (2017a, September 7). Report on offset agreements: evaluating current Jisc Collections deals. Year 2 - evaluating 2016 deals (Version 1). figshare. https://doi. org $/ 10.6084 / \mathrm{m} 9$. figshare.5383861.v1. 
Lawson, S. (2017b, May 9). Journal subscription expenditure in the UK 2015-16 (Version 6). figshare. https://doi.org/10.6084/m9.figshare.4542433.v6.

LIBER. (2017). Open Access: Five principles for negotiations with publishers.

Retrieved October 15, 2019, from https:/ /libereurope.eu/blog/2017/09/07/ open-access-five-principles-for-negotiations-with-publishers $/$.

Marques, M. (2017, March 6) Springer Compact agreement: first year evaluation.

Retrieved October 15, 2019, from https:/ / scholarlycommunications.jiscinvolve.org/ wp/2017/03/06/compact-agreement-first-year-evaluation/.

Morais, R., Bauer, J., \& Borrell-Damián, L. (2018). EUA big deals survey report - The first mapping of major scientific publishing contracts in Europe. Retrieved October 15, 2019, from https:/ / eua.eu/resources/publications/321:eua-big-deals-survey-report-thefirst-mapping-of-major-scientific-publishing-contracts-in-europe.html.

Morrison, H. (2018, February 6). DOAJ APC information as of Jan 31, 2018. Retrieved October 15, 2019 from https:/ / sustainingknowledgecommons.org/2018/02/06/ doaj-apc-information-as-of-jan-31-2018/9/.

National Library of Sweden. (2016). Sverige först $i$ Norden med ny modell för öppet tillgängliga forskningspublikationer. Retrieved November 30, 2017, from http://www. kb.se/aktuellt/nyheter/2016/Sverige-forst-i-Norden-med-ny-modell-for-oppettillgangliga-forskningspublikationer/.

National Library of Sweden. (2019). Kungliga bibliotekets årsredovisning 2018. Retrieved October 15, 2019, from https://www.kb.se/om-oss/styrning-ochorganisation/arsredovisningar.html.

Openaccess.nl. (2018). New agreement with Springer. Retrieved March 4, 2019 from https://www.openaccess.nl/en/events/new-agreement-with-springer.

Pieper, D., \& Geschuhn, K. (2016). From Offsetting to Pay-as-you-publish. The (potential) comeback of selection, individual prices and competition. Retrieved October 15, 2019, from https://septentrio.uit.no/index.php/SCS/article/viewFile/3943/3740.

Pinhasi, R., Blechl, G., Kromp, B., \& Schubert, B. (2018). The weakest link workflows in open access agreements: The experience of the Vienna University Library and recommendations for future negotiations. Insights, 31, 27, 1-11. https:// doi.org/10.1629/uksg.419.

Schimmer, R., Geschuhn, K. K., \& Vogler, A. (2015). Disrupting the subscription journals' business model for the necessary large-scale transformation to open access. https://doi. org $/ 10.17617 / 1.3$.

Science Europe. (2016). Briefing paper on open access business models and current trends in the open access publishing system. Retrieved October 15, 2019, from https://www.scienceeurope.org/wp-content/uploads/2016/04/SE Briefing_Paper OA Business Models.pdf. 
Springer Compact Agreement Netherlands (1.2015-12.2016). (2017). Retrieved March 4, 2019, from https://wisspub.files.wordpress.com/2017/07/dutch springer agreement 2015-2016.pdf.

Suber, P. (2012). Open access. Cambridge, MA: MIT Press.

SURFmarket. (n.d.). Springer Nature - License agreement. Retrieved October 15, 2019, from https://www.openaccess.nl/sites/www.openaccess.nl/files/documenten/ springer2018-2021 signed2.pdf.

Swedish Research Council. (2015). Proposal for national guidelines for open access to scientific information. Retrieved October 15, 2019, from https://www.vr.se/ english/analysis-and-assignments / we-analyse-and-evaluate/all-publications/ publications / 2015-03-02-proposal-for-national-guidelines-for-open-access-toscientific-information.html.

VSNU. (2017). Overview of costs incurred by universities for books and journals by publisher. Retrieved March 4, 2019 from http://www.vsnu.nl/en GB/ cost-of-publication.

\section{Notes}

\footnotetext{
${ }^{1}$ Springer and Nature Publishing Group (and Macmillan) merged into Springer Nature in 2015, but since their agreements are still negotiated separately it is still useful to discuss them separately.

${ }^{2}$ https://www.doaj.org/

${ }^{3}$ https://esac-initiative.org/

${ }^{4}$ http://swepub.kb.se/

${ }^{5}$ https://www.intact-project.org/openapc/

${ }^{6}$ Later 4,167 articles, as two more institutions joined (the Equality Ombudsman and Sophiahemmet University College) during the term. However, the analyses in this study were based on data from the 40 institutions that initially signed the agreement.

${ }^{7}$ https://www.intact-project.org/
} 